\title{
CÂNCER DE COLO UTERINO: atenção integral à mulher nos serviços de saúde
}

\author{
M arilu Correa SOARE Sa, Silvana M artins M ISH IM A ${ }^{\text {b }}$, Renata Cunha da SILVAc, \\ Caroline Vargas RIBEIRO d, Sonia M aria Könzgen MEIN CKE e, A na Cândida L opes CORRÊA ${ }^{f}$
}

\section{RESUMO}

O bjetivou-se compreender como os serviços de saúde do Sistema Ú nico de Saúde estão organizados para contemplar a integralidade na atenção à mulher com câncer de colo uterino. Pesquisa qualitativa, descritiva, com 20 mulheres. Utilizou-se na coleta dos dados a entrevista semiestruturada conjugada à observação participante. A análi ise temática evidenciou o tema "A procura pela assistência: 0 acesso ao Sistema Ú nico de Saúde e a utilização dos serviços na busca de atenção integral". I dentificou-se que, na utilização dos serviços de saúde, as mulheres expuseram concepções sobre a atenção recebida, as potencialidades e limites da integralidade nesse contexto. Conclui-se que a efetivação das ações de saúde, em busca da integ ralidade da atenção às mulheres, requer ousadia e a promoção do diálogo entre os atores sociais, como forma de construir uma consciência sanitária que permita 0 compromisso ético em direção às mudanças necessárias ao cuidado.

D escritores: E nfer magem oncológica. N eoplasias do colo do útero. Saúde da mul her. A ssistência integral à saúde.

\section{RESUMEN}

Seobjetivó comprender cómo los servicios del Sistema $\mathrm{N}$ acional deSal ud están organizados para hacer frentea la integralidad de la atención a la mujer con cáncer de cuello uterino. Investigación cualitativa, descriptiva con veinte mujeres. F ue utilizado en la recolección dedatos, la observación parti cipantey la entrevista semi estructurada. E I análisis temático reveló: $L$ a búsqueda de la atención: el acceso a SU S y el uso de los servicios de salud en la búsqueda de atención integral. Se identificó que las mujeres han puesto demanifiesto las concepciones acerca dela atención recibida, las potencialidades y los límites dela integralidad en este contexto. Se concluye que la eficacia de las acciones de salud en esta búsqueda requiere corajey la promoción del diálogo entre los actores sociales, como una manera de construir una conciencia de salud que permita el compromiso ético hacia los cambios necesarios para el cuidado.

D escriptores: E nfermería oncológica. N eoplasias del cuello uterino. Salud dela mujer. A tención integral de salud. T ítulo: Cáncer del cuello del útero: la atención integral a la mujer en los servicios de salud.

\section{ABST RACT}

This study aims to understand how the health services of the B razilian P ublic H ealth System (B P H S) are organiz ed to give an integral care to the w oman with cervical cancer. This is a descriptive, qualitative research with 20 women. Semi structured interviews were coupled with participant observation in data collection. T he thematic analysis revealed the theme: "T he search for care: access to B P H S and use of health services in the search for integ ral care". I n the use of heal th services, w omen haveexposed their view s on the recei ved care, and on the potentialities and limits of integrality in this context. Theconclusion is that the ef fectivation of heal th actions that aim at the integrality of carefor women requires courage and the promotion of a dialogue betw een social actors as a way to build a health aw areness that allows an ethical commitment pointing towards the necessary changes in care.

Descriptors: O ncologic, nursing. U terine cervical neoplasms. W omen's health. Comprehensive health care T itle: Cervical cancer: integral care to the woman in health services.

\footnotetext{
a D outora em Enfermagem em Saúde Pública, Professora Adjunta II da Faculdade de Enfermagem da U niversidade Federal de Pelotas (UF Pel), Pelotas, Rio G rande do Sul, Brasil.

b D outora em Enfermagem em Saúde Pública, Professora Titular da Escola de Enfermagem de Ribeirão Preto da U niversidade de São Paulo (EERP-USP), Ribeirão Preto, São Paulo, Brasil.

'E nfer meira, M estranda do Programa de Pós-G raduaçã̃o em E nfer magem da F aculdade de E nfermagem da U F Pel, Pelotas, Rio G rande do Sul, Brasil.

d Enfermeira Residente do Programa de Residência Integrada M ultiprofissional em A tenção à Saúde, Área de concentração Saúde da Criança.

e D outora em Enfermagem, Professora Adjunta II da Faculdade de Enfermagem da UF Pel, Pelotas, Rio G rande do Sul, Brasil.

f D iscente da F acul dade de Enfer magem da U F Pel, Bolsista de I niciação Científica do Conselho N acional de D esenvolvimento Científico e Tecnológico (CN P q), Pelotas, Rio G rande do Sul, Brasil.
} 


\section{INT RODUÇÃO}

0 câncer de colo uterino (CCU) é um problema de saúde pública que compromete a saúde das mulheres, alterando a qualidade de vida em um estágio da existência em que elas, muitas vezes, estão estruturando sua vida familiar, profissional e social. Q uando diagnosticado na fase inicial, as chances de cura são de $100 \%$ e existem evidências científicas que comprovam formas simples, eficientes e eficazes para o rastreamento desse tipo de câncer, bem como para a detecção das lesões precursoras $^{(1)}$.

T anto a incidência como a mortalidade por câncer do colo do útero podem ser reduzidas com programas organizados de rastreamento. Nos países desenvolvidos, a partir da implantação de programas de rastreamento de base populacional, uma expressiva redução na morbimortalidade pela doença foi al cançada ${ }^{(2)}$.

0 câncer do colo do útero é o segundo tipo de câncer mais comum entre as mulheres, com aproximadamente 500 mil casos novos por ano no mundo, sendo responsável pela morte de 230 mil muIheres por ano. No Brasil, para 2010, são esperados 18.430 casos, com um risco estimado de 18 a cada 100 mil mulheres ${ }^{(1)}$.

A integralidade da atenção na saúde das muIheres também pressupõe que estas, em algum momento de suas vidas, fizeram uso dos serviços de saúde para atendimento de seus problemas e necessidades, ou de seus familiares. M omento este em que poderiam ter sido orientadas quanto à importância dos cuidados necessários à prevenção do agravo ou para sua detecção precoce.

Os anos de 1980 e 90 foram palco de propostas de mudança na organização do sistema de saúde brasileiro. 0 movimento da Reforma Sanitária é considerado o ponto de partida das mudanças no campo da saúde, sendo que a Constituição Federal de 1988 materializou as discussões e propostas desse movimento, possibilitando a instituição do Sistema Ú nico de Saúde (SUS), apontando diretrizes para organizar a atenção e o cuidado à população(3).

Instituído o SU S, mecanismos foram sendo desenvolvidos com a finalidade de articular ações e serviços, buscando a construção de um sistema de saúde cujas diretrizes legais propunham uma direção única, em cada esfera de gover no, indicando o movimento de descentralização da gestão(3,4).
A construção de um sistema de saúde único, acessível, igualitário e com qualidade é um desafio que ainda está em construção. A saúde tem que ser compreendida de forma ampliada, e as políticas e práticas sociais precisam buscar estratégias de enfrentamento da dura realidade brasileira, marcada por tantas desigualdades. Os grandes problemas na atenção à saúde, como 0 acesso desigual, a inadequação dos serviços quando confrontados com as necessidades, a ausência de atenção integral, o paralelismo da oferta e a baixa qualidade dos serviços delimitam as orientações para a reestruturação de modelos de atenção(3).

No contexto preconizado pelo SU S, a organização da atenção elege um conjunto de princípios éticos e estratégicos para conferir robustez à conquista da saúde como direito de cidadania. Reconhece-se ainda que os desafios para al cançar as mudanças no aparato legal e na estrutura políticoadministrativa das instituições nos direcionam para inovações no modo de gestão do SU S, na gerência e na organização do trabalho em saúde. Associa-se, ainda, no contexto do SU S a humanização da saúde na perspectiva da construção de redes comprometidas com a produção de saúde dos usuários do sistema, os quais, por sua vez, são estimulados ao exercício da autonomia, co-responsabilidade e participação no processo de saúde individual e coletiva ${ }^{(3,5)}$.

U m conjunto de inovações vem desafiando a organização do sistema de saúde brasileiro, traduzido por uma pressão para a incorporação de um contingente populacional que estava excluído do acesso à atenção à saúde; uma demanda por uma qualidade na atenção; a progressiva incorporação de tecnologias nos serviços; e a definição de critérios de equanimidade para a distribuição de recur$\operatorname{sos}^{(4)}$.

Nesse contexto, parece ser de fundamental valor o desenvolvimento de ações que articulem os aspectos educativos, preventivos e assistenciais, voltados à manutenção da saúde. A ções que visem o preparo dos indivíduos para o exercício da cidadania com consciência, pois contar com a participação da comunidade na formulação e implantação de novas políticas de saúde multiplica as possibilidades de sucesso do processo. D estaca-se aqui a categoria de integralidade como referência para a produção do cuidado à saúde e para a necessidade de articulação de diferentes instâncias de atenção. 
Entende-se que a integralidade na assistência à saúde deva ser pensada como um processo que envolve a vida das pessoas, suas histórias, suas vivências, seus anseios, suas expectativas. E considerando as questões de demanda e necessidades da comunidade, articuladas com a atuação dos trabalhadores de saúde, rumo a uma abordagem multiprofissional e interdisciplinar para o cuidado à saúde.

Portanto, a garantia de integralidade pressupõe o estabelecimento de ações que permitam a interligação entre os diferentes serviços disponibilizados à população, em seus diversos níveis de atenção à saúde. 0 M inistério da Saúde, mais recentemente, passou a trazer em documentos oficiais a ideia de rede para o trabal ho em saúde, relacionando a proposta com os princípios e diretrizes do SU S e com a atenção integral à saúde ${ }^{(6,7)}$.

A ssim, ações para o fortal ecimento de um modelo de atenção que busque, por meio de estratégias de promoção e prevenção, 0 atendimento ao princípio da integralidade da assistência têm sido propostas nas políticas públicas de saúde. N esse sentido, a integralidade configura-se como o fio condutor da organização dos serviços e da educação permanente dos trabalhadores de saúde.

Diante do exposto, elaborou-se o seguinte questionamento: Os serviços de saúde do Sistema Ú nico de Saúde estão organizados de modo a contemplar a integ ralidade na atenção à mulher com câncer de colo uterino? Para respondê-lo, traçouse como objetivo deste estudo compreender como os serviços de saúde do SUS estão organizados para contemplar a integralidade na atenção à mulher com câncer de colo uterino.

\section{MET ODOLOGIA}

A presente investigação utilizou uma abordagem qualitativa, descritiva. Para os procedimentos analíticos, optou-se ela análise temática, seguindo as etapas de ordenação, classificação e análise ${ }^{(8)}$.

Seguindo as normatizações presentes na $\mathrm{Re}$ solução 196/ 96 do Conselho N acional de Saúde ${ }^{(9)}$, o projeto da pesquisa foi encaminhado para análise junto ao Comitê de Ética em Pesquisa da Faculdade de $M$ edicina da U niver sidade F ederal de PeIotas, sendo aprovado sob o Parecer no 030/ 06.

Os dados secundários originaram-se das informações do Sistema de I nformação do Câncer do Colo do Ú tero (SISCOLO). A captação dos dados primários ocorreu no período de junho a dezembro de 2006 e teve como local de coleta o domicílio, o local de trabalho e a U nidade Básica de Saúde (UBS) das mulheres identificadas com diagnóstico de CCU, entre os anos de 2003 a 2005.

Para viabilizar a coleta dos dados empíricos, optou-se pela entrevista semiestruturada, como técnica de pesquisa, por possibilitar a introdução de certos questionamentos básicos e até aprofundar outras questões que pudessem surgir no transcorrer da entrevista(8). T ambém foi utilizada a técnica de observação para a complementação dos dados empíricos. A proposta de observação teve a finalidade de acompanhar as mulheres em seguimento nos serviços de saúde para tratamento radioterápico e/ ou quimioterápico, momento no qual a pesquisadora, na qualidade de observadora participante, procurou captar as situações de atendimento à mulher em tempo real, com registro em diário de campo.

Participaram deste estudo 20 mulheres identificadas por meio dos registros do SISCOLO para os anos de 2003-2005 e que preencheram os critérios de seleção: diagnóstico comprovado de CCU realizado na rede pública de saúde do município, no período de 2003 a 2005; ser moradora do município do estudo; consentir na gravação da entrevista; permitir acompanhamento durante o tratamento na quimioterapia e/ ou radioterapia, para observação; disposição para participar do estudo; permitir a divulgação dos dados no meio científico. Para garantia do anonimato, as mulheres foram identificadas por nomes fictícios de sua escolha.

\section{RESULTADOS E DISCUSSÃO}

O tema depreendido na análise dos dados e abordado neste artigo é "A procura pela assistência: 0 acesso ao Sistema Ú nico de Saúde e a utilização dos serviços na busca de atenção integral".

D esafios ainda são colocados, quando ol hamos para a organização dos serviços de saúde na perspectiva da atenção integral. Produzir cuidados de saúde para a mulher como um todo, na expressão de suas necessidades e problemas, independente da fase do ciclo vital ou da sua condição como trabaIhadora, é considerar uma lógica de ação que nos direcione a apreender as necessidades individuais e coletivas das mulheres, em seu contexto social.

Assim, as mulheres entrevistadas neste estudo tinham o entendimento de que os serviços de 
saúde ainda não conseguem atender a população de forma satisfatória, apontavam falhas e responsabilizam os gestores do sistema, mas também se reconheciam como sujeitos ativos, para buscarem os seus direitos a serviços de qualidade.

A cho que nossos ser viços de saúde ainda não conseguem nos atender em tudo. Há muitas fal has não só da parte dos profissionais, mas também da parte dos responsáveis pela Secretaria da Saúde da cidade, do estado e até do país. P enso que as pessoas que usam o SU $S$ deveriam ser mais ativas na busca de seus direitos, não ficarem esperando que as coisas aconteçam, redamem e cobrem um atendimento decente. $\mathrm{N}$ ós deveríamos ter mais participação. E u estou tentando ir nas reuniões do bairro, para ver se consigo ajudar de alguma maneira (Beatriz).

Dizer que nossos governantes precisam olhar com mais carinho a saúde das pessoas, pois está tudo muito largado, ninguém se compromete com nada, é muito roubo, muito desvio de dinheiro que deveria ser empregado na saúde (D alva).

A fala de Beatriz demonstra um movimento da mulher para a concretização da integralidade no cuidado:

[ ...] nós deveríamos ter mais partici pação e reclamem e cobrem um atendimento decente [ ...] (Beatriz).

A credita-se que posicionamentos como os acima citados possibilitariam o surgimento de uma nova cultura, voltada para as necessidades de saúde das mulheres.

Essa participação e a reclamação podem assumir o caráter de essas mulheres estarem mais próximas aos processos de decisão e controle dos serviços de saúde, de modo a per mitir que os princípios de universalidade e integralidade estejam efetivamente presentes no cotidiano dos serviços.

$\mathrm{N}$ a observação, essa concepção de um atendimento ruim no SU S foi verbalizada pelo familiar (Dinorá), que adotou uma postura de "vigilância" durante o tratamento de sua mãe $D$ janira.

[ A familiar Dinorá referiu que, quando foi feito diagnóstico de câncer da sua mãe, ficou muito receosa de que 0 atendimento fosse ruim] . [ ...] Quando vim com minha mãeaqui, já fui mepreparando para o pior [ ...] . [ O bserva-se que Dinorá está sempre atenta a toda movimentação junto de sua mãe, indaga sobre a medicação, solicita a presença dos trabalhadores de saúde constantemente, fato que parece incomodar $D$ janira que retruca] [ ...] J á falei para ela que as meninas sabem o que estão fazendo, acho muito chato isso [...] (Diário de Campo Djanira, 06/ 07/ 2006)

A concepção do SU S como um ser viço no qual se é mal atendido e onde há demora reforça a possibilidade da alternativa de pagamento, para acelerar o processo de atenção à saúde em outros serviços de saúde.

E u queria salientar uma coisa. $\mathrm{N}$ em todos os exames eu consegui pelo SU S. T ive que pagar alguns exames, uma ultrassonografia transvaginal, abdominal total foi pago, porque são exames que levam cer to tempo pelo SU S. A pessoa entra em uma lista de espera e, como a gente queria isso rápido para poder começar a sessão de radioterapia, aí paguei por fora. P elo SU S não tem chegar e ser atendida, tem fila para marcar e fazer os exame. E u já sabia que demorava, aí che guei nos locais e perguntei: "Q uero fazer determinado exame Q uanto custa?" M ostrei a requisição, disse que tinha pressa e qual era o problema. E u não procurei pelo SUS, porque eu sabia que ia demorar mesmo (T hereza).

Entretanto, ao experienciar 0 atendimento, a mulher se surpreendeu com a resolubilidade e teve a possibilidade de mudar sua concepção sobre o SUS.

[ ...] aquela ideia, poisfalam tanta coisa assim, né? E u pensava: "Vou ter que esperar, vai custar, vou ter que pagar". A chei que teria que pagar antes, porque, no mesmo dia que ele me deu os exames que eu tinha que fazer, a mãejá saiu marcando. E o meu médico ligava, para ver se conseguia agendar mais rápido, explicando o caso. E le foi muito interessado. E u achei que ia demorar, queia ser mal tratada, a gente ouve cada história... A gora mudei meu pensamento com relação ao SUS mas fui muito, muito bem tratada [ ...] (Fernanda).

É assim mesmo, a nossa saúde está em maus lençóis, mas eu queria me tratar e não podia pagar particular, então o negócio era enfrentar o SU S. E te digo quefoi tranqüilo mesmo, até me surpreendi (Silvana).

Com relação às dificuldades enfrentadas pela mulher, a maneira com que os trabalhadores do sistema de saúde atendem na marcação de exames, com desinteresse, má vontade e falta de paciência, contribui para uma avaliação negativa do SUS. 
[...] meu neto é que caminhou para marcar e me levava no dia. Caso contrário, ah!... não fazia mesmo, pois é muita burocracia, muito correcorre.. D epois, é tudo muito demorado, as pessoas não têm paciência e eu, que já estou velha, menos ainda, né? $\mathrm{E} u$ acho que essa demora prejudica, porque, se eu fosse esperar os dois me ses que ia levar para marcar para eles me atenderem, eu não ia chegar atélá, morria antes, com certeza [ ...] (N ancy).

E u sabia que não ia ser fácil, porque tu ouves as pessoas reclamarem da demora, da falta de informação, de paciência, dos er ros médicos... é muita dificuldade (Silvana).

Essa postura dos trabalhadores compromete a integ ralidade, quando pensamos os diferentes saberes e práticas envolvidos na atenção à mulher nos diversos serviços por ela frequentados, na busca de cuidado. É preciso despertar no trabalhador e na mulher que a integralidade das ações se dá a partir da composição de vários saberes e nas diferentes práticas de produção de cuidado em saúde, realizadas para atender as necessidades de saúde dos usuários ${ }^{(10)}$.

Acredita-se que as práticas de saúde devem ser exercidas pelos trabalhadores de saúde por meio da utilização do conhecimento científico, mas não podem dispensar a atenção, o cuidado, a escuta e 0 acolhimento, que favorecem a formação do vínculo entre os trabal hadores e usuários. A o se pensar 0 trabalho em saúde, aponta-se que as tecnologias leves são entendidas como aquelas que possibilitam a construção de vínculos no momento em que se dá a produção do cuidado e do acolhimento, constituídas pelas relações entre 0 trabalhador de saúde e o usuário(11).

Contudo, para Beatriz, 0 atendimento no SUS foi caracterizado pelo descaso e falta de atenção dos trabalhadores. $M$ as ela também referiu um atendimento qualificado, com o profissional preocupado em explicar o que estava fazendo. Sua fala demonstra a importância do trabalhador de saúde desenvolver uma interação marcada pelo diálogo com o cliente, pois, nesse dialogar, poderemos alcançar a tão almejada relação sujeito/ sujeito.

Foi complicado, até a doutora me disse: "Como ninguém descobriu que tu tinhas essa doença, se tu sempre foste uma pessoa controlada?". E u disse para ela: "Vou ser sincera, eu notava que não era bem atendida. P orque eles não me examinavam". Por exemplo, ela me colocava sentada na cadeira e me dizia: "Vou ter quete colocar esse líquido, para ver se tem uma massa, aí a gente olha com microscópio". Explicava cada passo do que ia fazer. J á os outros não, era tudo no ligeirinho mesmo, às vezes mal davam bom-dia e, num piscar de olhos, tu já estavas fora do consultório. É um total descaso com a gente T em dias que, enquanto uma se vestia, a outra já estava tirando a roupa (Beatriz).

F requentemente detectam-se reclamações quanto à insensibilidade e indiferença dos trabaIhadores de saúde ao sofrimento humano e às extensas filas de espera nas U BSs e nos pronto atendimentos; as reclamações dos usuários quanto ao funcionamento do sistema de saúde e conflitos de insatisfação das equipes tor nam evidente a necessidade de mudança no atual sistema ${ }^{(12-14)}$.

A formação do vínculo com os trabalhadores de saúde possibilita agilizar outros atendimentos no sistema de saúde e reforça a integralidade, como princípio potencializador do cuidado. Elvira referiu que, três anos antes, não tinha essa facilidade, o que, de cer ta forma, levava a acreditar que houve avanço no atendimento do usuário.

É muito complicado 0 atendimento no posto. E m 2003, quando foi feito o diagnóstico de meu câncer, eu reclamava muito do atendimento. E ra demorado, confuso, muito vai e vem, muitos exames, e principalmente muita ansiedade T u quer resolver o teu problema com urgência e nem sempreé possível. H oje eu vejo que já me Ihorou um pouco, mas, naquele tempo, se fosse conversar contigo, com certeza ia redamar muito. A té porque hoje eu faço revisão todo ano, religiosamente, e já tenho uma amizade com o pessoal do posto (E Ivira).

0 que me deixou tranquila foi 0 apoio que recebi da médica. Sabe aquela coisa assim como se fosse de minha família? F ui tão bem tratada, acolhida, mimada mesmo, ela se preocupou com minha doença, agilizou os exames e até hoje, passados todos estes anos, se pre ciso de alguma coisa, corro pra ela ( $M$ arcele).

O M inistério da Saúde preconiza que as diferentes práticas profissionais têm relação com as difer entes possibilidades de lidar com o momento de encontro com o usuário. N esse encontro, são mobilizados sentimentos, emoções e identificações que facilitam ou dificultam a interação, pois existem profissionais com maior ou menor facilidade para conversar, para se relacionarem com os usuários $^{(15)}$.

No encontro de duas ou mais pessoas há uma interação comunicativa, não necessariamente ver- 
bal, levando à formação do vínculo. Ele depende da qualidade da interação, da compreensão da fala, da disponibilidade para a escuta. Dessa maneira, a interação-vínculo será positiva, quando promover transformações criativas e inovadoras, para satisfação das necessidades ${ }^{(16-18)}$.

No processo de cuidar em saúde, entendese que a formação de trabalhadores de saúde realmente comprometidos com os princípios do SU S permite a construção das relações entre os sujeitos, de forma a propiciar o envolvimento, a troca e o diálogo. Para prestar uma atenção cuidadosa ao usuário, é necessário desvelar seus sentimentos, conhecer as situações por el e vivenciadas, a fim de viabilizar formas concretas e efetivas de cuidar ${ }^{(16)}$.

\section{CONCLUSÕES}

A importância de conhecer as práticas de atenção à saúde e a maneira como se efetivam, no cotidiano do trabal ho, para a produção do cuidado, tanto para a área da gestão, quanto da organização dos serviços de saúde, são de relevância para a configuração da integralidade. N ão somente como princípio do SU S, mas também como boas práticas de saúde, para a melhoria do cuidado à saúde dispensado aos usuários do SU S.

0 acesso universal à atenção integral à saúde de qualidade, contudo, parece ainda não estar contemplado no cotidiano dos serviços de saúde, mesmo com todo o amparo jurídico-legal dos princípios e diretrizes do SUS. Há um distanciamento entre os trabal hadores de saúde e os usuários, entre as equipes e a comunidade, e entre os trabal hadores e seus meios de trabal ho.

A integralidade, não apenas como princípio do SU S, mas, sobretudo, como exercício de boas práticas na atenção e cuidado à mulher, se expressa também na escuta, no vínculo, nas concepções que as mulheres, os trabalhadores de saúde e os gestores do sistema de saúde apresentam das formas de fazer saúde, e como atentam para a possibilidade de coparticipação no processo de construção de saúde para todos.

A efetividade das ações de saúde, em busca da integ ralidade da atenção, requer ousadia e a promoção do diálogo entre os atores sociais, como forma de construir uma consciência sanitária que permita o compromisso ético em direção às mudanças necessárias, para o alcance do SU S que merecemos.

\section{REFERÊNCIAS}

1 M inistério da Saúde (BR), Instituto Nacional de Câncer, Coordenação de Prevenção e Vigilância de Câncer. E stimativas 2010: incidência de câncer no Brasil. Rio de Janeiro; 2009.

2 World $\mathrm{H}$ ealth Organization, International Agency for Research on Cancer. G lobocan [ I nternet] . L yon; 2008 [ cited 2009 Sept 10] . Availabl efrom: http:/ / globocan. iarc.fr.

3 Costa AM, Guilhem D, Silver LD. Planejamento familiar: a autonomia das mulheres sob questão. Rev Bras Saúde M ater I nfant. 2006;6(1):75-84.

4 Ceccim RB. E ducação permanente em saúde: descentralização e disseminação de capacidade pedagógica na saúde. Ciênc Saúde Colet. 2005;10(4):975-86.

5 Koerich M S, Backs DS, M archiori M C, Erdmann AL. Pacto em defesa da saúde: divulgando os direitos dos usuários pela pesquisa-ação. Rev G aúcha Enferm. 2009;30(4):677-84.

$6 \mathrm{M}$ endes EV. As redes de atenção à saúde. Ciênc Saúde Colet. 2010;15(5):2297-305.

7 Saúde M IBM . Interrogando a operação da rede de serviços de saúde [ tese] . Ribeirão Preto: E scola de Enfermagem de Ribeirão Preto, U niversidade de São Paulo; 2006.

8 M inayo M CS. 0 desafio do conhecimento: pesquisa qualitativa em saúde. 8aed. São Paulo: H ucitec; 2007.

9 M inistério da Saúde (BR), Conselho N acional de Saúde. Resolução 196, de 10 de outubro de 1996: diretrizes e normas regulamentadoras de pesquisa envolvendo seres humanos. Brasília (D F ); 1996.

10 G omes M CPA, Pinheiro R. A colhimento e vínculo: práticas de integralidade na gestão do cuidado em saúde em grandes centros urbanos. I nterface Comun Saúde E duc. 2005;17:287-301.

11 Sá M C, A zevedo CS. Subjetividade e gestão: explorando as articulações psicossociais no trabalho gerencial e no trabalho em saúde. Ciênc Saúde Colet. 2010;15(5):2345-54.

12 Grisotti M , Patrício ZM , Silva A. A participação de usuários, trabal hadores e conselheiros de saúde: um estudo qualitativo. Ciênc Saúde Colet. 2010;15(3): $831-40$. 
13 G astão W SC. 0 SU S entre a tradição dos Sistemas $\mathrm{N}$ acionais e o modo liber al-privado para organizar o cuidado à saúde. Ciênc Saúde Colet. 2007;12 (Supl):1865-74.

14 Carvalho SR, Campos GW S. M odelos de atenção à saúde: a organização de equipes de referência na rede básica da Secretaria M unicipal de Saúde de Betim/ $M$ inas $G$ erais. In: A nais da 10a Conferência Nacional de Saúde On-Line; 1996 set 2-6; Brasília (DF), Brasil [ Internet] . Brasília (DF); 1996 [ citado 2007 jul 10] . D isponível em: http:/ / www.datasus.gov.br/ cns/ temas/ tribuna/ CNS_Art_Betim_agosto99.htm.

$15 \mathrm{~F} \mathrm{ranceschini} \mathrm{T} \mathrm{RC.} \mathrm{Observação} \mathrm{da} \mathrm{relação} \mathrm{mãe-bebê-}$ família como uma ferramenta para o aprendizado da integralidade [ dissertação] . Ribeirão Preto: Escola de E nfer magem de R ibeirão P reto, U niversidade de São Paulo; 2005.
16 T eixeira CA B, Silva RM , Rodrigues M SP, L inard AG, Diógenes M AR, M endonça FAC. Comunicação interpessoal como instrumento que viabiliza a qualidade da consulta de enfermagem ginecológica. Rev APS. 2009;12(1):16-28.

17 Franco T B. As redes na micropolítica do processo de trabalho em saúde. In: Pinheiro R, M attos RA, organizadores. Gestão em redes. Rio de Janeiro: CEPESC-IM S/ UERJ-LAPPIS; 2006. p. 459-74.

18 M inistério da Saúde (BR), Secretaria de G estão do T rabal ho e da E ducação na Saúde, D epartamento de $\mathrm{G}$ estão da E ducação na saúde. Curso de formação de facilitadores de educação per manente em saúde: unidade de aprendizagem: trabal ho e relações na produção do cuidado em saúde. Rio de Janeiro; 2005.
E ndereço da autora / Dirección del autor /

\section{A uthor's address:}

A na Cândida L opes Cor rêa

Rua Santa Cecília, 327, Santa Terezinha

96065-410, Pelotas, RS

E-mail: analopescorrea@ hotmail.com
Recebido em: 05/ 12/ 2010

A provado em: 25/ 07/ 2011 